\title{
A VARIAS BANDAS. LA COSA LITERARIA
}

\author{
Julián SANTOS GUERRERO \\ Universidad Complutense de Madrid \\ jsantosg@ filos.ucm.es
}

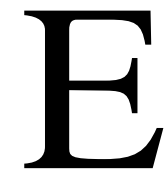
mpezar alargando la mano, con el gesto corporal que sujeta el Rollerball 0,7 que vierte tinta negra en trazos de 0,7 milímetros. Movimientos rítmicos apenas percibidos que van lentamente encadenando los grafemas, las líneas de sentido. El texto se perfila despacio sobre el papel cuadriculado de un cuaderno apoyado en la mesa; como se dibujan las espirales de una bayeta esponja en la encimera de cualquier cocina: sin tomar conciencia de la actividad corporal. Todo hecho a través de un automatismo sólido, con la vista un poco perdida hacia fuera para concentrar en la mente el sentido impuesto a las palabras escritas, a las frases encadenadas.

Es preciso limpiar, y decidir las palabras adecuadas, apropiarse de la lengua para poder firmar. Desechar las ideas vagas y los conceptos inadecuados, cocer el pensamiento. Pero las palabras resbalan como el jabón, no se dejan apresar fácilmente. Puestas a hervir, dan vueltas desordenadas mientras sueltan su jugo sabroso y se mezclan con otros aromas para formar un texto propio. Será preciso probarlo después, leerlo al final para estampar debajo el nombre, al dorso, para arriesgar la firma. Por ahora las ideas se encuentran desordenadas, en una profusión sin conexión alguna, flotando, sin presión ni temperatura.

Comenzamos por un desvío, no puede hacerse de otro modo. Así, sin quererlo la cosa, fabricando una escena inventada donde alguien hace varias cosas a la vez, donde algo se escribe cocinando, borrando, limpiando y rayando, trabajando a dos manos. Mientras, rueda la bola (ball 0,7) que impregna por una cara y se impregna de tinta por la opuesta, dejando su rastro en el papel. Mojando por abajo y mojándose por arriba: sujeto y objeto a la vez de esa pequeña imprenta de mano que se mueve verticalmente, algo inclinada, con una grácil erección. Por debajo, el papel esponja acoge de la bola metálica la tinta pegajosa, del utensilio que se dosifica, que se retiene en cada eyección: la bola da cierre y apertura, es la válvula, la bomba de achique literaria que hace un rato 
estaba parada, retenida en la punta del artefacto de pie y mezclado entre otros parecidos en el cubo de los «bolis», a la espera de una cirugía que ahora comienza a dejar su cifra sobre el papel en blanco. Como un utensilio de cocina: «modesto, ligero, netamente especializado en su utilidad, bastante poco brillante, un poco relumbrón sin embargo, de pequeña envergadura y que se mantiene en las manos sin pesar mucho» (Ponge, 1961: 181).

Poco a poco en el ir y venir de la mano y de la mente, del cuerpo animado y del mecanismo inyector del Rollerball 0,7 el escrito se constituye en la superficie del papel, rodando la bola, señalando algunas frases en torno a una pregunta. La pregunta por la cosa, por la cosa literaria. El escrito quiere hacer lo que dice que hace. Escribiéndose, haciéndose cosa literaria quiere decir lo que es o podría ser la cosa literaria. Una manera ciertamente ingenua de comenzar. Haciendo un remedo, un guiño algo zafio al trabajo de Francis Ponge y a la lectura que de él realizó Jacques Derrida en Cerisy-la-Salle, con ocasión del coloquio en torno a la obra del poeta y celebrado entre el 2 y 12 de agosto de 1975.

Pero lo cierto es que más allá de las críticas que el firmante pueda dirigir contra su propio texto (más adelante pondremos en cuestión esta propiedad), habría que decir que no se trata de un simple recurso retórico o de una estrategia literaria más o menos cándida, sino de una imposibilidad. Es imposible salir de la estructura circular de ese movimiento, porque un escrito es siempre una cosa, una cosa literaria o susceptible de convertirse en cosa literaria. Y si el escrito se empeña en la pregunta por la cosa literaria, el círculo se cierra. Lo preguntado está ya implícito en la pregunta, da lugar a la pregunta. O, dicho de otro modo, sólo se puede preguntar, preguntar por escrito se entiende, si al preguntar se hace uso de lo preguntado. De algún modo la respuesta está ya en la pregunta, porque un escrito ya es una cosa, decíamos, pero también porque toda cosa tiene el carácter de una escritura. Ya se sabe: para Derrida la escritura invade todo el campo del ente ${ }^{1}$.

Este trabajo en círculo que aparece cada vez que se trata de arte, tiene un largo recorrido en la filosofía (los nombres de Kant, Hegel o Heidegger serían desde luego imprescindibles), si bien la reflexión que aquí se inicia puede dar pistas sobre esa circularidad, sobre la contumacia de este recurso cada vez que se piensa el arte.

\footnotetext{
${ }^{1}$ «La huella, donde se marca la relación con lo otro, articula su posibilidad sobre todo el campo del ente, que la metafísica ha determinado como ente-presente a partir del movimiento ocultado de la huella. Es necesario pensar la huella antes del ente» (Derrida, 1967: 61).
} 


\section{Intervinientes a varias bandas}

Comenzamos pues por un desvío, por un lateral, por una banda y por una venda que rodea un libro regalado, por un don y por un relato asimismo, por una anécdota que Derrida comenta al final del libro Signéponge, en un epílogo a la obra que lleva por título «Après coup (Les Preuves)». Un relato. «Je dois vous raconter»:

Dos días después [de haber pasado a máquina el discurso con el cual se ha dirigido al público en Cerisy] por tanto, hojeaba todavía encima de mi mesa, donde él había permanecido, este ejemplar del Nouveau Recueil que el mismo Francis Ponge me había traído, una noche que cenábamos en casa de [...]. Hojeando el libro incluso sin saber lo que buscaba en él o quizás sin buscar nada en él, observo entonces la banda del libro. Esa especie de anuncio publicitario estaba plegado en dos entre las páginas y yo lo había guardado como una suerte de marca páginas.

Esta banda la conocía bien por haber admirado de ella, no hacía mucho, la cantidad de juego que daba -pero, como se dice, la había olvidado, debía haberla olvidado.

¿Qué dice la banda? Esto:

\section{BANDE \\ A FAIRE SAUTER.}

[...] Ahora bien, lo que he tenido la certeza, en conciencia, de leer por primera vez esta tarde del 23 de julio son esas dos palabras en caracteres más pequeños y negros, en el ángulo, abajo y a la derecha:

BANDE

A FAIRE SAUTER.

signé: Ponge»

(Derrida, 1984: 119-121).

Comenzamos por este pequeño relato de un olvido, y por esta banda que cerraba y rodeaba el libro que Francis Ponge había regalado a Derrida siete años antes. Una banda para romper, para hacer saltar, para liberar de este modo la lectura. Ahora bien, como señala el mismo Derrida, también puede leerse esa palabra primera, «bande», como un imperativo del verbo bander que viene a decir en español: «vendar», también «tensar», incluso en una acepción muy vulgar «empalmarse». De aquí por tanto: venda, tensa o empálmate hasta hacer saltar. La cuestión es ¿hacer saltar qué?, ¿a quién? Derrida se lo pregunta también, y responde: «à vous de décider mais cela peut se faire en lisant» (Derrida, 1984: 120). Después del relato nos da así la palabra. Nos toca decidir; es nuestro turno. Se necesita llevar las cosas al límite, la cosa libro, para hacerla saltar; romper, romperse para darse a leer. Una banda también, una banda circular que en su superficie pone lo que es: «Esto es una banda». Como si en el círculo se cerrara la cosa y el nombre de la cosa, como si la cosa, banda, encerrara los nombres, los constriñera en un apretado vínculo entre las palabras y las cosas.

Nos toca decidir lo que hay que hacer saltar mediante una tensión; pero hay una pista: «puede hacerse leyendo». Por debajo del rótulo de la banda: «firmado: Ponge». Es 
la cita de la firma, no tanto la firma sino la cita de la firma, Derrida lo subraya. Pero también es el título del libro de Derrida. Así se llama, Signéponge: FirmadoPonge (signé, firmado), firmadoesponja (éponge, esponja), signoesponja (signe, signo)... ¿Hacer saltar qué? La decisión puede hacerse leyendo. Leer es saltar de una palabra a otra, ligarlas y, en cierto sentido, vendarlas, unirlas con una cinta estrecha de sentido hasta hacerlas saltar. Dar sentido es una operación que consiste justamente en la realización de esos saltos, de pasos y de referencias, de envíos y de ligaduras. Saltar la banda y saltar de banda. A varias bandas.

Otra banda. En este caso se encuentra en la contraportada de un libro doble, el que publicaron Geoffrey Bennington y Jacques Derrida en 1991. En la página 14 aparece la fotografía sacada en la casa de éste preparando ambos la edición del libro. Bennington se encuentra detrás de Derrida, que está escribiendo sobre el teclado de su ordenador, mientras aquél, de pie, con una mano apoyada sobre la silla ocupada por JD, le señala la pantalla a la cual éste mira con atención. Como una escena dentro de otra escena, sobre la mesa puede observarse de un modo muy ostensible aquella «tarjeta postal» que reproduce el grabado en el que aparece Sócrates escribiendo y Platón detrás con un gesto indicador, al modo quizás de dictarle al viejo su escritura. Los nombres de los dos filósofos están escritos por encima de sus cabezas. El mismo gesto de Bennington por detrás de Derrida.
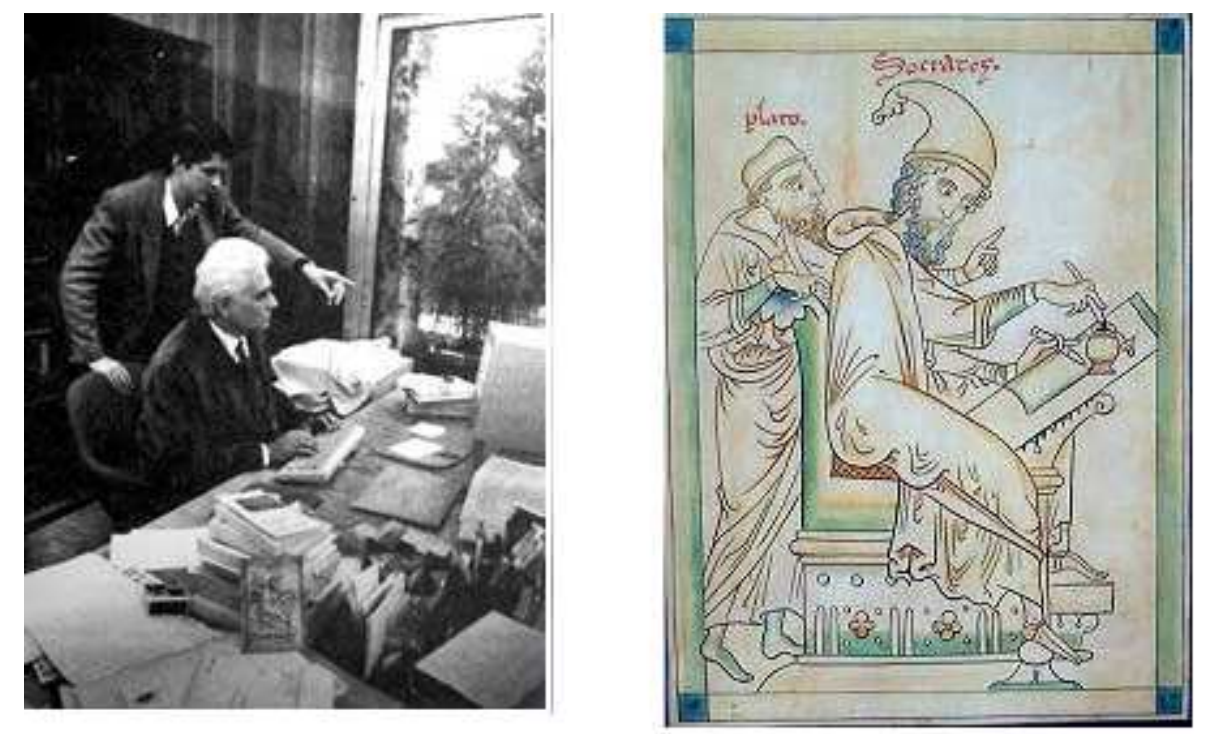

Leemos en otro libro, «Envíos»:

«Mira bien esta tarjeta, es una reproducción. Te digo en secreto este aforismo solemne y sentencioso: ¿acaso no empezó todo entre nosotros con una reproducción? Sí, y a la vez nada es más sencillamente falso, he ahí la tragedia [...]». Apostamos por la tarjeta postal antes que por la literatura, la inadmisible literatura. ¿Viste esta tarjeta, la imagen al 
dorso de esta tarjeta? Di con ella ayer, en la Bodleian (es la famosa biblioteca de Oxford), ya te contaré (Derrida, 1980: 18, con pequeñas variaciones de traducción).

Al inicio del largo envío postal («Envíos») que contiene cientos de referencias a la famosa tarjeta, justo al día siguiente de comenzar la escritura. La fecha en el texto citado es el 4 de junio de 1977. Se trata del tercer envío, el primero es del 3 de junio, y el segundo, apenas unas líneas, del mismo 3 de junio. Los envíos llegan, recordemos, hasta el 30 de agosto de 1979. Una fecha es ya una firma ${ }^{2}$. Todos los párrafos de «Envíos» están fechados, esto es, firmados. Y todas esas firmas están ahí, en la fotografía de ese otro libro de los dos, de Bennington y JD. Un libro que lleva por título: Jacques Derrida por Geoffrey Bennington y Jacques Derrida. El nombre del libro contiene dos veces el nombre del autor. El objeto sobre el que se escribe y el autor que lo escribe, objeto y sujeto. Como una banda circular: «Esto es una banda», «Esto es Jacques Derrida», lo dice Jacques Derrida y otro. Firma y contrafirma. Nombre del autor a través del otro, por el otro. El autor como otro que se ve, se mira, como lector también de sí mismo, como narrador que se da a sí mismo su propia autoría, su propia narración por medio de esas bandas o esas vendas de sentido que contienen, que estrechan también, que estrangulan, «à faire sauter», la identidad del autor. Un autor que se da en cuanto que se escribe, se monumentaliza, se erige o se pone en pie, a través de ese juego colosal $^{3}$ de las vendas, como otro. Banda, pues, como conjunto, como pluralidad; banda y bandido también que supone que «nada es más sencillamente falso»: «¿acaso no empezó todo entre nosotros con una reproducción?».

De hecho, al pie de aquella fotografía en casa de Derrida podemos leer: «Carte postale ou tableau vivant» («Tarjeta postal o cuadro vivo»). Escena, cuadro escenográfico, escena de representación, escena viva. Unas líneas a continuación de ese «cuadro vivo», y en el mismo pie de foto, aparece una frase verdaderamente abismal. Se citan las últimas palabras de la parte del libro conjunto escrita por Bennington, que se titula «Derridabase». Allí, en esa «base», el autor británico termina con un parágrafo al que titula «Envío» (ya nos hemos percatado antes de estos reenvíos), el final de este parágrafo es asimismo el final de Derridabase. Allí puede leerse: «Por eso es que este

\footnotetext{
${ }^{2}$ «En ciertas condiciones al menos, fechar viene a ser firmar» (Derrida, 1986: 29).

${ }^{3}$ El motivo del Colossos aparece citado en múltiples ocasiones en Signéponge, (Derrida, 1986: 13, 22, 42, 48, 88, 99...). La cuestión había sido trabajada por Derrida en «Le colossal» (Derrida, 1978: 136-168) dentro del capítulo dedicado a la Crítica del Juicio kantiana y titulado «Parergon». No es este el lugar de hacer una glosa del complejo entramado que allí se expone; pero baste aquí la siguiente indicación: «Colosal (kolossalisch) califica por consiguiente la presentación, la puesta en escena o en presencia, la aprehensión por la vista de algo, pero de algo que no es una cosa, ya que es un concepto [en el caso de Kant, por supuesto]. Y la presentación de ese concepto en tanto que no es presentable. Ni simplemente impresentable: casi impresentable. Y en razón de su tamaño: es "casi demasiado grande". Este concepto se anuncia y se oculta a la presentación sobre la escena. Se diría, en razón de su tamaño casi excesivo, obsceno» (Derrida, 1978: 143). En cuanto a su relación con el doble, es imprescindible remitir al trabajo de Jean-Pierre Vernant titulado «La categoría psicológica del doble» (Vernant, 1965).
} 
libro no os servirá de nada, a vosotros otros, a vosotros, al otro, y no habrá sido sino un pretexto encubierto para inscribir en él mi propia firma detrás, en su espalda» (Derrida-Bennington, 1991: 15). ¿En la espalda de quién?, ¿de Derrida o del libro? ¿De JD? La fotografía parece decirlo así. ¿Del libro de Bennington? Puede ser, también el libro se llama Jacques Derrida. La frase es toda una declaración de contrabando, de contrabandeo, de contrafirma incluso. El libro es un pretexto encubierto para la firma, un pre-texto. Lo previo al texto, o el texto previo que pasa de contrabando porque lo que se ve es la firma, la firma de su autor que firma en la espalda de Jacques Derrida, en la espalda del libro y del «corpus» de $\mathrm{JD}^{4}$. Sabemos que ese «Derridabase» es una compilación del corpus de obra de Derrida; de ahí el título.

Y bien, sin embargo la firma a la vuelta del libro, del volumen se entiende, de la cosa-libro, es una frase. Reza así:

\section{Dès qu'il est saisi par l'écriture, le concept es cuit. JACQUES DERRIDA}

La contraportada, la espalda del libro, está en blanco, sólo esas frases en el centro. Están firmadas, o mejor dicho, con la firma citada de JD. Allí también la frase, una frase que ya es por sí una firma ${ }^{5}$, un acta de propiedad que lleva inscrita la singularidad de su autor. Pero recordemos las palabras de Bennington: «para inscribir en él mi propia firma detrás, en su espalda». Tal vez la frase en la espalda del libro sea de Bennington y ahora la contrafirma lo sea de Derrida. Éste podría decir: «Sí, esta frase es de GB y yo, JD, lo confirmo. Yo soy el contrafirmante». Puede incluso que esa firma esté contrabandeada. Y es que el acto de la firma, el acontecimiento de tiempo y lugar, de aquí y ahora de la firma, su singularidad, sólo puede ser bajo la condición de posibilidad de su iterabilidad, de su repetición posible ${ }^{6}$. Esto es, la condición de posibilidad de su singularidad, del por primera vez, por única vez («¿acaso no empezó todo entre nosotros con una reproducción?»), lo es también de imposibilidad de esa misma única vez.

La banda que rodea el texto, que lo comprime hasta hacerlo saltar, leer, abrirse al otro, es asimismo la puesta en escena del nombre propio, la escena de la firma. En ese «libro de firmas» que es «Envíos» (que curiosamente lleva el mismo título, si bien en plural, que el último parágrafo de Derridabase) puede seguirse el hilo de esa condición

\footnotetext{
${ }^{4}$ En Signéponge, puede leerse refiriéndose a Ponge: «Pero las palabras son también cuerpos, trozos de su cuerpo, las extremidades donde le lleva su cuerpo de empuñador» (Derrida, 1984: 58).

5 Derrida distingue en Signéponge (Derrida, 1984: 46, 47) tres modalidades de firma: la firma en sentido propio, las marcas idiomáticas que un signatario abandonaría o calcularía en su producto, y la que puede llamarse firma general o firma de la firma. Aquí nos referimos a la segunda clase de firma.

${ }^{6}$ «Para funcionar, es decir, para ser legible, una firma debe poseer una forma repetible, iterable, imitable; debe poder desprenderse de la intención presente y singular de su producción. Es su mismidad lo que, alterando su identidad y su singularidad, divide el sello» (Derrida, 1972: 371).
} 
del envío, de la distancia, del espaciamiento que, al recaer sobre sí (y todos esos «Envíos» vuelven a sí, a sí mismo, a Jacques Derrida que tras enviarlos los publica bajo su nombre, los lee, los edita, los hace públicos, se los envía de nuevo a sí mismo), expone la separación de sí, y mete por medio al otro, la alteridad y el espaciamiento que la escritura lleva consigo, la muerte en el mecanismo propio de la vida, en la propiedad de la vida: la vida la muerte. Este reenvío es la vuelta a sí a través del otro, y como otra escena del fort/da freudiano ${ }^{7}$ constituye el mecanismo escritural de la construcción del nombre, del nombre propio. Y así como aquella escena «autobiográfica» de Más allá del principio del placer (la del fort/da) es el modo de hacer saltar, de dar un salto (faire un bond) y meter en la escritura el cuerpo en su aquí y ahora, así también en esa banda, en esa venda que rodea el libro Jacques Derrida, se expone otra escena de escritura que viene a convertir el cuerpo en corpus, en cosa, en cosa ahí delante («en su espalda»), y que gracias a las vendas se aparece, erecto, como un doble o un aparecido, un revenant que vuelve, y al volver espectraliza la firma.

La firma de la banda es la petrificación del nombre en la frase lapidaria, lo cual no deja de ser una puesta en abismo, una especulación sin fondo. Si leemos otra vez la frase del dorso, la grabada en la espalda del libro, a su vuelta, la frase que le da la vuelta y da la vuelta a las cosas, se nos aparecerán algunos intervinientes de esta escena.

«Dès qu'il est saisi par l'écriture, le concept es cuit». Desde que es saisi, desde el momento en que es saisi por la escritura, el concepto está cocido, en el sentido también de hecho, listo o terminado. Pero ¿cómo traducir saisi? El verbo francés saisir se emplea en el ámbito culinario para decir en castellano «soasar» o, lo que es igual, asar ligeramente, dejar la carne a medio asar, por ejemplo. De aquí por tanto una traducción: desde que es soasado por la escritura, el concepto está hecho, cocido. Lo que haría pues la escritura sería someter al concepto a un fuego muy vivo y retirarlo enseguida, dejar su huella tan sólo, de manera que quede simplemente marcado; pero eso para el concepto es ya estar hecho, cocido y, por consiguiente, dispuesto para su deglución, para servirlo, para ponerlo a la mesa, a disposición de cualquiera, del otro. La marca de paso, de trasiego o de paso al otro, la marca que le da paso al concepto es, pues, la escritura. Si no es así, el concepto no está hecho, esto es, no es un concepto. Esa señal de la escritura, sin embargo, lo deja a medio hacer, siempre abierto entonces a otro paso. Hecho pero no del todo. Siempre cabe otra vuelta más, otra pasada, otra vuelta en el «vuelta y vuelta» (ésta sería otra traducción de «saisi»).

Lo que hace la escritura no es reducirlo o consumirlo, sino marcarlo en cierto modo, firmarlo, sellarlo, y por eso mismo imprimir en él la marca del otro, la señal, la

\footnotetext{
${ }^{7}$ Derrida había trabajado esa escena freudiana en «Especular - sobre "Freud"» (Derrida, 1980).
} 
seña de una alteridad en el seno mismo de la concepción originaria. Escritura y concepción: «¿acaso no empezó todo entre nosotros con una reproducción?».

Pero todavía no ha terminado este cambio de banda que es la traducción, aún quedan más matices y más vendas que tensar en esa irreducible luxación que es el paso a otra lengua. Saisir dice también coger, apoderarse de algo o de alguien, y se utiliza en el ámbito policial para señalar la acción de prender a un bandido (saisir un bandit) o para decomisar o intervenir la mercancía de contrabando. Ahora la escritura prende, pero ¿a quién prende? A él, «Dès qu'il est saisi par l’écriture». ¿Y quién es él? Los dos personajes están cogidos por la escritura, vinculados por ella (Littré: Saisir, 'Terme de marine. Lier étroitement deux objets par des cordages ou de toute autre façon'; 'Término de marina. Unir estrechamente dos objetos mediante jarcias o de otra forma'), por las vendas de la escritura. Cualquiera de los dos puede firmar. Cogidos, hechos escritura, convertidos ya en cosa de escritura, en corpus literario, cualquiera puede ser «il»: Sócrates, o Platón, Derrida o Bennington, Francis Ponge o Derrida. Al pasar a la escritura toda firma es falsificable, toda firma es, podría decirse, «literaria», todas llevan ya, se quiera o no, la marca del otro, el hierro o el sello que la soasa ( «Sí, y a la vez nada es más sencillamente falso, he ahí la tragedia.»). Ligadura con él o ella, con ello, estrechamente vinculado por cuerdas o vendas. Verdaderamente, después de estas conclusiones, el concepto est cuit, está condenado, arruinado, ha perdido su crédito. Su unidad y su homogeneidad se resquebrajan; el concepto se reparte, listo para su reapropiación, se da a comer, se comparte, se parte: está tocado de muerte (Littré: Cuit, 'Familièrement. Il est cuit, c'est un homme cuit, c'est-à-dire sa fortune est ruinée, son crédit est perdu; ou, dans un langage plus que familier, il va mourir'; 'Familiarmente. Está cuit, es un hombre cuit, es decir su fortuna está arruinada, su crédito está perdido; o, en un lenguaje más que familiar, va a morir').

Esta catástrofe del concepto en la banda, en el juego de bandas entre Derrida y Ponge (no es este el lugar para seguir el minucioso y apasionante protocolo elaborado por Derrida entre las dos columnas de Glas, en torno al concepto en Hegel, columna izquierda, y el bander, el empalmarse como «concepto» en la literatura de Jean Genet. Baste aquí sólo el apunte y la consideración de esta inversión catastrófica: el concepto que re-eleva al signo, lo acoge, lo apresa y lo supera en tanto que deviene erección del concepto. Es aquí «prendido» por la escritura, marcado por ella en la intimidad de su concepción, tocado de muerte: «El movimiento de la erección a la inversa describe la estructura de la concepción no conceptual del concepto» [Derrida, 1974: 95, columna izquierda]. «L'érection tombe»-«la erección cae»; también, «la erección tumba»- sería el motivo tantas veces repetido en los textos de Derrida), esa catástrofe del concepto, decimos, no significa que no haya conceptos o que se invierta la jerarquía de su valor 
con respecto al signo, más bien quiere decir que la conceptualización (incluida la conceptualización filosófica) siempre ha puesto en juego un modo de escritura y, así, no puede concebirse el concepto si no es ya erguido por la venda que le hace saltar. La venda de la escritura que hace presente lo que estrangula.

Es la concepción, la paternidad también, la que da el nombre. Y bien, saisie par l'écriture, intervenida o requisada por la escritura, puesto ahora a la luz su contrabando, ella resulta repetible y con ello desapropia de su propiedad el nombre propio, lo que hace de toda firma una falsificación posible, incluso la que se cita bajo ese nombre, a saber, JACQUES DERRIDA.

\section{Los términos del contrato}

Pero hay dos lados, dos bandas en toda esta escena. La venda une, liga, vincula y estrangula; venda «para hacer saltar», saltar la banda, paso de banda, pasar a la otra banda, recordemos. Banda de JD: lo cocido del concepto-la firma. Banda de FP: la cosa banda-la firma. Las firmas de los intervinientes serán las claves, las clavijas también.

Tanto en el texto de Cerisy como en la entrevista concedida por Derrida a finales de 1991 a Gérard Farasse (Derrida-Farasse, 2005) se encuentra subrayado especialmente el contrato entre Ponge y la cosa. Eso que pasa entre ambos es justamente el espacio en el que la lectura de JD se inserta, se interesa:

Lo que interesa, nos interesa, nos compromete a leer, es forzosamente aquello que ocurre en el medio, entre ellos: los intermediarios (nombres y cosas), los testigos, los intercesores, los acontecimientos que ocurren entre ellos, los interesados (Derrida, 1984: 46).

Y lo que se contrata entre ellos es una obligación. La cosa demanda, obliga al poeta Francis Ponge, pero esta obligación es imposible. ¿Cómo decir el nombre de la cosa? La cosa permanece muda, no dice su nombre; hierática en su presentación rechaza el intercambio que abre el nombre. Resistente en su singularidad la cosa no se deja apresar en la economía de los nombres, no se deja deglutir en el signo, en la palabra que la introduce en un intercambio sin barreras. Ésta será la imposibilidad de la cosa. Ahí, en silencio ante el poeta, le retira la palabra en un acto de violencia y de autoridad. Ella no es un objeto cuyo ser se agota en estar ahí delante; por el contrario, con una insistencia tenaz, terca, abrumadora, ejerce una presión, le exige al poeta. En ese mismo acto autoritario de su presentación le demanda $s u$ nombre, la firma del acontecimiento de su venida a ser, la marca diferencial que señala su singularidad de cosa. Double bind de la cosa, doble mandato que somete a una imposibilidad aquello que al mismo tiempo impone de forma ineludible. Es en ese mandamiento doble y contrapuesto de la cosa donde el poeta se juega su ser o no ser, su reputación también y su nombre. 
Esta imposibilidad no se ciñe a la orden de hacer algo que no es posible; no es una imposibilidad fáctica, sino una imposibilidad ontológica. Lo que la cosa demanda es, precisamente, lo imposible. Esto lo señala Derrida de una manera contundente:

\footnotetext{
El duelo entre rivales y el don van hasta la muerte. La cosa permanece otro cuya ley demanda lo imposible. No pide esto o aquello, algo que resultaría ser imposible. No, demanda lo imposible, demanda eso mismo que es imposible, lo demanda por imposible y porque esa imposibilidad misma es la condición de posibilidad de la demanda (Derrida, 1984: 18).
}

De hecho, decir el nombre de la cosa sería en cierto modo decir el don por el que la cosa viene a ser, lo que tiene ella de acontecimiento, «su envío del ser», por poner una frase de tinte heideggeriano. Ese efecto de propiedad quedaría borrado por el nombre en cuanto inclusión en un mecanismo de comunicación y, por ende, de intercambio y de repetibilidad. Es preciso convertir la cosa en signo para que ese mecanismo funcione, pero ello trae consigo la borradura o la mancha, si se quiere, de esa propiedad, de la inmaculada propiedad de su venida. La demanda de propiedad es así pues la demanda de firma, de la firma de la cosa. Es esta la razón por la cual al llevar a la firma esa alteridad resistente de la cosa, esa firma lo es ya del otro, firma de lo otro de la cosa o de «la cosa que permanece otro». Y es de eso otro de donde dimana esa ley que demanda lo imposible.

La condición que hace posible esa demanda, la imposibilidad que la hace posible, es la venida de la cosa como envío en un juego de relaciones y de reenvíos. De ahí también la relación de exigencia que mantiene con el poeta. Esto es así porque la cosa no es una entidad previa a su venida o a su establecimiento en el juego de relaciones, sino precisamente eso que acontece (que acontece como cosa) en ese juego. Mirado así, una cosa viene constituida por lo que ella no es, por otros, por los otros, y esa alteridad resulta estructuralmente implícita en el ocurrir mismo de la cosa. La cosa no está saturada en su ser, sino que permanece siempre abierta a la relación, en la relación; lo que viene a decir también que una cosa siempre puede ser otra, devenir otra. La alteridad irreducible opera desde siempre en la cosa, y de este modo se «inscribe» en la cosa como imposibilidad. Una alteridad sin referentes ni referencias, sin posibilidad tampoco, que sin embargo constituye la singularidad de la cosa, su firma: la firma lo es del otro.

En rigor ocurre lo mismo con el nombre de alguien, con el nombre propio, con la propiedad del nombre que vincula eso que habría venido a llamarse «el mundo de los hechos» con el del lenguaje. En cuanto signo de un solo referente (digamos así en principio) el nombre propio conectaría de manera unívoca los dos ámbitos; no obstante, si el nombre es nombre, a su carácter indicativo ha de ponérsele también su iterabilidad. Así pues, la repetición está «inscrita» en su misma nominación propia, y lo hace además 
como inclusión en un sistema de clasificaciones propuesto ya en la gramaticalidad de una lengua. El nombre propio que guarda la nominación borra la propiedad, y a la inversa. Así ocurre con la firma, con la firma como marca del «yo aquí y ahora», del acontecimiento singular de la propiedad del nombre.

Digamos que, en ambos casos, el nombre de la cosa y el nombre propio se encuentran cogidos en una misma cuestión:

Sobre la sola instancia del nombre [prénom], se ve ya la doble banda [el doble mandato] de la firma tirante entre la exigencia de devenir cosa, nombre común de cosa o nombre de una generalidad que pierde el idiom para inscribir lo colosal; y del otro lado la demanda contraria de una idiomaticidad pura, mayúscula inmaculada por lo común, condición de la firma en sentido propio. La firma jeroglífico, la firma metonímica o anagramática son la condición de posibilidad y de imposibilidad, el double bind de un acontecimiento de firma. Como si la cosa (o el nombre común de la cosa) debiera absorber lo propio, beberlo y retenerlo para guardarlo. Pero al tiempo, guardándolo, bebiéndolo, absorbiéndolo, es como si ella (o su nombre) perdiese o ensuciase el nombre propio (Derrida, 1984: 54).

A partir de aquí dar nombre es en cierto modo cosificar, retener, fijar o erigir el coloso como «representación de lo irrepresentable», y al mismo tiempo perder la cosa, lo que tiene de singular, de acontecimiento. Pero también guardar el acontecimiento como alteridad, como otro, como firma del otro, como imposibilidad misma: acontecimiento sin acontecimiento.

Todo ello se juega en el contrato: por un lado el contrato entre la cosa y el nombre, entre la imposibidad de la cosa y su nombre imposible. Por el otro lado el contrato entre Ponge y su firma, entre Ponge y su nombre propio, su nombre que deviene nombre común o nombre de cosa: signéponge, signo-esponja-firma-Ponge, firma-esponja. Porque un nombre firmado puede convertirse en una pieza, en una piedra entre otras. $\mathrm{Y}$ entre esos contratos a su vez, como una puesta en abismo, el contrato entre la cosa y Ponge, la demanda imposible de la cosa dirigida al poeta Francis Ponge. Sin embargo todos esos contratos están incumplidos de antemano porque están desajustados, porque obligan a lo que no se puede cumplir. Ninguno de ellos es equilibrado, homogéneo y equitativo para las partes. El cumplimiento significa en cierto sentido la anulación del contratante (tal vez por ello dice el propio Ponge «que nunca se había ocupado más que de la muerte». Derrida, 1984: 27). Porque, y esto es lo que es preciso comprender del modo más radical, no hay partes con anterioridad al contrato. Las partes lo son por el contrato, y justamente por la imposibilidad misma de esa contratación. Es pues la banda o la venda de escritura, la firma del contrato (firma vinculante pero sin acontecimiento, sin nombre propio, firma que absorbe la propiedad y erige no obstante el coloso pétreo), la representación de lo irrepresentable, el acontecimiento de venida a ser de las partes y asimismo su firma en piedra, firma 
cosificada en aquella pizarra de Cerisy-la-Salle: SIGNÉPONGE. Es decir, firma del otro. De eso otro que firma.

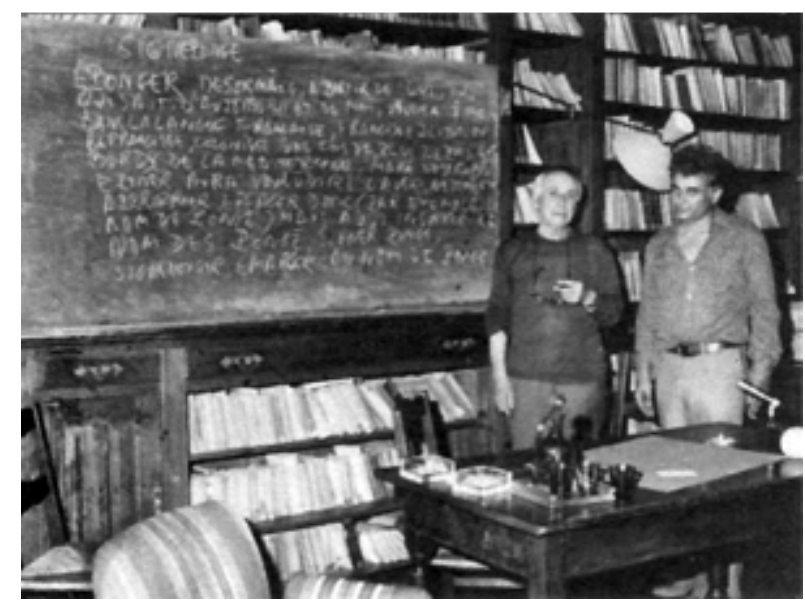

Así dice Derrida:

La cosa no es alguna cosa que se conforme a unas leyes de las cuales yo tendría que hablar de manera objetiva (adecuada) o por el contrario subjetiva (antropomórfica). Antes que nada la cosa es lo otro, lo totalmente otro que dicta o que escribe la ley, una ley que no es simplemente natural (lex naturae rerum) sino un mandato infinitamente, insaciablemente, imperioso al cual debo someterme, libre para intentar saldarlo a continuación, al final del duelo entre rivales, después de haberle ofrecido, con mi vida y mi deseo, alguna cosa así como mi firma (Derrida, 1984: 17).

Pero también insiste Derrida en su escrito: «"Francis Ponge será mi cosa". Esto debe darnos a experimentar la ley de la cosa» (Derrida, 1984: 16). Francis Ponge, el nombre, Francis Ponge, la firma, Francis Ponge, la franquicia y el franqueamiento de la esponja. Signeponge como acontecimiento de escritura, como acontecimiento que borra el acontecimiento, como acontecimiento literario. Y es que la firma es el vínculo entre el cuerpo y el corpus literario. Como una venda estirada entre ambas firmas, como una escritura que se estira hasta hacerla saltar (à faire sauter), como una venda esponjosa y elástica donde la firma se escribe, cuerpo de escritura, subyectil ${ }^{8}$ esponja, cavernoso, agujereado, poroso, entintado: «Francis Ponge será mi cosa». Pero al tiempo, la cosa es lo otro, y «Francis Ponge es mi cosa» quiere decir que «Francis Ponge», el nombre, la cosa, la firma, la escritura, es un otro.

\footnotetext{
${ }^{8}$ Este es otro motivo que atraviesa como un proyectil el cuerpo de Signéponge, Derrida lo cita en el centro del libro, en la página 56, refiriéndose a la esponja, al cuerpo-esponja: «Es una notable figura del receptáculo, un subyectil para la escritura» (Derrida, 1984: 56). No podemos seguir aquí esta preciosa indicación que nos llevaría al cuerpo en Antonin Artaud. Para seguir este hilo: Derrida-Thévenin, 1986. Fue precisamente en casa de Yves y Paule Thévenin donde tuvo lugar la escena relatada por Derrida en la que Ponge le entrega el libro cuya banda fue «olvidada» por Derrida. Él lo narra, como hemos visto, en un «Après coup» añadido al final de Derrida, 1984: 119.
} 
Ahí, en el intercambiador de la firma (eso es lo que la cosa exige y lo que FP pone en riesgo, da, intentando con ello saldar la deuda insaldable) hay un salto que desajusta todo contrato. No hay, no puede haber relación con el otro. El otro es lo que está fuera de toda relación, lo que no se da a representación alguna, el salto de la banda, «contrabando» puro que rompe con la ley en el origen mismo de la ley, de la demanda de la cosa (aquella frase, «Francis Ponge es mi cosa», «debe darnos a experimentar la ley de la cosa»). Entre el lenguaje y la cosa, los nombres y las cosas, la puesta en abismo (recordemos, el nombre también es la cosa, la esponja). Ese «entre» otro, más viejo que los nombres y las cosas, origen del sentido y asimismo sin sentido (y esta podría ser otra traducción más de la banda del libro de Derrida y Bennington, una traducción delirante, desbordada, pasada de banda: «Dès qu'il est saisi par l'écriture, le concept es cuit», «en cuanto está pillado por la escritura, el concepto está borracho». «Enganchado a la escritura, el concepto delira»-être cuit, fam. «estar borracho»-), desvío en el origen. Eso otro no intercambia nada, no dice nada, no transacciona con nada; abre una puesta en abismo donde nada ni nadie se presenta como tal. Tan sólo la erección de las vendas, del monumento, del coloso literario, del corpus literario, de un desvío sin tregua que multiplica al infinito (puesta en abismo) los representantes. Y tensa, comprime la tensión del tractus, hasta hacerse saltar, como una banda elástica que se contrae, contractus, hasta hacer pedazos la firma del contrato, la firma esponja; hasta multiplicar en una diseminación sin vuelta al padre la simiente del sentido, como una nueva signatura rerum.

La estructura de la puesta en abismo, tal como él [FP] la practica, me parece repetir cada vez esta escena, cada vez, pero cada vez de manera necesariamente idiomática, la «cualidad diferencial» que afecta hasta a la forma de la firma, permaneciendo ésta del otro. De ahí viene la monumentalización infinita pero también la disipación sin retorno de la firma, que no está ya vinculada a un solo nombre propio sino a la multiplicidad ateológica de una nueva signatura rerum (Derrida, 1984: 44).

Este salto por los aires, el fraccionamiento infinito de este franquear el paso, de dar paso (pas, paso y negación) entre una banda y otra, de abrir un paso franco (Francis, Francis Ponge) en la lengua francesa, (signéponge no existe como tal palabra en la lengua francesa) libre de deudas, de imposición fiscal, en «contrabando»-extraño contrato entre contrabandistas- pone en juego la baza literaria.

\section{Esponjar las firmas}

Volvemos nuevamente a la catástrofe, a la catástrofe del concepto y a la catástrofe del signo; por eso es preciso matizar, hilar más fino, dejar tal vez el 0,7 en nuestro Rollerball para ir más abajo en la escala de finura, de hiladura en la «bayeta-esponja», 
en el signo «esponja» entresacado de la literatura de Ponge, de Francis Ponge, de esa esponja que franquea el paso entre las bandas:

El signo esponja es un nombre, entre comillas, si quieren, el signo «esponja», tanto el nombre de la esponja que es un signo, como el nombre del signo, que es también, lo hemos verificado, una esponja. El nombre de la esponja es un signo, la esponja es un signo. Además el signo es Ponge (Derrida, 1984: 83).

No se trata de ninguna inversión, de ninguna ausencia que venga a cubrir el lugar con un sustituto fetiche del padre muerto. Las vendas no rodean nada, no amortajan al muerto. Debajo de las vendas no hay nada, ellas son desvío, envíos; y la esponja es el signo, el signo del vendar, de adherir bandas y tensarlas, de apretarlas, de estrujar, contraer, contratar con las cosas haciendo venir las cosas como desvíos, en la marcha lateral de un crustáceo, como caminan lateralmente las gambas, por ejemplo. El texto de Derrida, Signéponge, es también otra esponja, otro signo esponja, la ex-apropiación de la esponja de Ponge, la firma del otro sobre la firma propia, el paso de banda, una nueva vuelta más del vendaje.

Como la esponja, Signéponge es esponjoso, cavernoso, lleno de entradas y salidas a otros textos de Derrida. Este trabajo aquí presente podría haber sido eso, y en vez de cogerse tan sólo a un hilo, una venda, o una banda, podríamos habernos cogido a muchos más. La esponja, la bayeta-esponja, la gamuza traza círculos en la cocina, y podríamos haber cogido otros ingredientes, otros intervinientes. Para terminar cabría tal vez hacer una lectura de uso, de forma de uso de esa esponja que es también Signéponge, de ese utensilio de cocina para apresar conceptos, para absorberlos -o para soasarlos o para emborracharlos también- (evidentemente Derrida no dice eso dentro de los múltiples usos de la esponja, pero sí dice citando a Ponge, absorbiéndolo, diríamos, de su obra La Seine: «Capaz alternativamente de lo gaseoso y de lo líquido, "de llenarse de viento o de agua", la esponja es sobre todo la escritura. Como toda cosa» (Derrida, 1984: 59).

El estatuto de la esponja es precisamente ser intermediario, entre animal y vegetal, entre el ser vivo y simple cosa, entre vivo y muerto. Intermediario sin más, como el escrito, como el corpus del escrito, y en ese sentido:

Si puede ponerse en todos los estados, servir de intermediario, de intercesor o de testigo universal, la esponja constituye no solamente el término de una analogía (alegoría o metáfora) sino también por añadidura el medio de todas las figuras, la metaforicidad misma (Derrida, 1984: 60).

Por ello, y a modo de cierre de este escrito, bien podrían señalarse algunas de la formas de establecerse ese vínculo por la intercesión de la esponja: 
- El vínculo se traza por especulación y por representación sin presente.

- Le es necesaria al vínculo una interrupción, un salto, el espaciamiento del otro.

- El vínculo por representación deviene representación de la representación, esto es, puesta en abismo.

- Puesta en abismo significa interrupción (sin relación), y asimismo la multiplicación descontrolada, sin vuelta al padre: diseminación de la firma.

- Lo que vincula del vínculo, lo que une, es justamente el desvío, el paso de banda. Ello dice siempre otra cosa. La cosa, el sentido mismo de la cosa, siempre puede ser otra cosa. De ahí el riesgo de la interpretación.

- Añade algo, alguna cosa: toda cosa tiene ya el paradigma del parergon, de cosa añadida, de no esencialidad.

- La esponja es un hallazgo de Derrida, una suerte, una chance que abre el acontecimiento literario de Signéponge. Un acontecimiento que comporta su iterabilidad: acontecimiento sin acontecimiento.

- La esponja vincula porque es el «paradigma de la cosa misma como otra cosa, cosa otro inaccesible, sujeto imposible». Ejemplo sin valor de ejemplaridad.

- Abre la economía del signo, del intercambio, pero no tiene valor, no tiene precio. Es sin precio a fuerza de ser singular. Vínculo sin vínculo. Doble banda.

Como fin de este escrito es preciso recordar las frases con las que Derrida comenta la afirmación de Gérard Farasse según la cual los textos de Ponge no derivan hacia el símbolo:

Ni símbolo ni metáfora, ni hermenéutica, aunque ellos reclaman todo eso. Reclaman irresistiblemente el desciframiento teórico o interpretativo aun cuando se resisten a ello: lo que abre la hermenéutica por definición, no se entrega a ella, permaneciendo inaccesible y heterogéneo a aquello mismo que así viene a ser posible (Derrida-Farasse, 2005: 25).

Seguimos escribiendo, y a la escucha del reclamo que hace ese acontecimiento de lectura que fue Signéponge, también irreducible a nuestra interpretación, ya lo sabemos. Ya hace muchas palabras que hemos dejado de escribir con el Rollerball 0,7. Se terminó la tinta. Seguimos con un Hi-Tecpoint 0,5 que encontramos en el cubo de los «bolis». $\mathrm{Su}$ punta tiene una suerte de esponja, como un rotulador, que absorbe la tinta de un depósito a la vista, es mejor para evitar sorpresas cuando la tinta se agota. En cualquier 
caso, dejamos por el momento de escribir, el Hi-Tecpoint se reúne con el Rollerball 07 gastado pero del que me resisto a desprenderme, vuelve con él al cubito de los «bolis», pero no por ello dejará de esponjar y de pedir nuevamente a la mano que se alargue para seguir escribiendo.

VULIAN SANTOS GUERRERO

\section{Bibliografía}

DERRIDA, J. (1967): De la gramatología. México, Siglo XXI, $3^{\text {a }}$ ed., 1984.

— (1972): Márgenes de la filosofía. Madrid, Cátedra, 1989. (1974): Glas. Paris, Galilée.

(1978): La vérité en peinture. Paris, Flammarion (la traducción de las referencias a esta obra es nuestra).

- (1980): “Envíos”, en La tarjeta postal. De Sócrates a Freud y más allá. México, Siglo XXI, $2^{\text {a }}$ ed., 2001.

— (1984): Signéponge. Paris, Éditions du Seuil, 1988 (la traducción de las referencias a esta obra es nuestra).

- (1986): Schibboleth, pour Paul Celan, Paris, Galilée (la traducción de las referencias a esta obra es nuestra).

(1986) "Forcener le subjectile", en P. Thévenin y J. Derrida, Antonin Artaud. Dessins et portraits. Paris, Gallimard.

DERRIDA, J., y BENNINGTON, G. (1991): Jacques Derrida par Geoffrey Bennington et Jacques Derrida. Paris, Éditions du Seuil (la traducción de las referencias a esta obra es nuestra).

DERRIDA, J., y FARASSE, G., (2005): Déplier Ponge. Paris, Presses Universitaires de Sptentrion (la traducción de las referencias a esta obra es nuestra).

PONGE, F. (1961): “L’ustensile”, en Méthodes. Paris, Gallimard, 1988 (la traducción de las referencias a esta obra es nuestra).

VERNANT, J.-P. (1965): Mito y pensamiento en la Grecia clásica. Barcelona, Ariel, $2^{\text {a }}$ ed., 1985. 